\title{
Developing an emergency ultrasound app - a collaborative project between clinicians from different universities
}

\author{
Kim Thestrup Foss ${ }^{1,2^{*}}$, Yousif Subhi ${ }^{1,3}$, Rasmus Aagaard ${ }^{4,5}$, Ebbe Lahn Bessmann ${ }^{1,6}$, Morten Thingemann Bøtker ${ }^{4,7}$, \\ Ole Graumann ${ }^{8,9,10,11}$, Christian B. Laursen ${ }^{11,12}$, Jesper Weile ${ }^{4,13}$ and Tobias Todsen ${ }^{1,14}$
}

\begin{abstract}
Focused emergency ultrasound is rapidly evolving as a clinical skill for bedside examination by physicians at all levels of education. Ultrasound is highly operator-dependent and relevant training is essential to ensure appropriate use. When supplementing hands-on focused ultrasound courses, e-learning can increase the learning effect. We developed an emergency ultrasound app to enable onsite e-learning for trainees. In this paper, we share our experiences in the development of this app and present the final product.
\end{abstract}

Keywords: Focused ultrasound, Medical education, Medical mobile applications, mHealth, e-learning, Video-assisted learning

\section{Letter to the Editor}

Focused ultrasound is rapidly expanding in emergency care in both prehospital and hospital settings, but ultrasound is operator-dependent and requires adequate training [1-3]. Ultrasound courses provide the trainees with confidence in clinical use [4] and e-learning is excellent course-preparation [5]. Clinicians frequently use smartphones for educational purposes and an app could potentially provide e-learning support for hands-on training in focused ultrasound [6]. We sought to develop a non-commercial smartphone app for focused ultrasound in emergency settings independent of financial interests. The purpose of this letter is to report on the process developing a clinical teaching app, and to present the final product.

We formed a group of Danish physicians engaged in ultrasound teaching and research. Our goal was to produce a smartphone app with standardized national instructions on how to conduct focused ultrasound in an emergency setting. Engaging physicians from different

\footnotetext{
* Correspondence: kimtfoss@gmail.com

${ }^{1}$ Centre for Clinical Education, Centre for HR, Capital Region of Denmark \& University of Copenhagen, Copenhagen, Denmark

2Department of Neurology, Copenhagen University Hospital Herlev, Herlev, Denmark

Full list of author information is available at the end of the article
}

hospitals, universities, and specialities enabled us to elevate instructions beyond local practice to be nationally applicable. Skype (Skype Technologies, Luxembourg) was used for meetings to discuss the content of the app and gain consensus about nomenclature and probe orientation. We agreed that an introduction to focused ultrasound and five specific focused ultrasound protocols (focused lung ultrasound, focus assessed transthoracic echocardiography, ultrasound guided vascular access, extended focused assessment with sonography for trauma, and limited compression ultrasonography for deep venous thrombosis) would be appropriate. Main authors were selected for each protocol-section and a manuscript was drafted and shared with the other authors using Dropbox (Dropbox Inc., USA) for review. After review by the other authors, the main authors finalized each section. Video-demonstrations were recorded in Clinical Skills Laboratories at Centre for Clinical Education (Copenhagen, Denmark). Videos were recorded with three-point lighting setup and three video cameras installed on tripods with a portable microphone for audio. Ultrasound cine-loops were recorded directly from the ultrasound machines (from GE Healthcare, UK and BK Medical, Denmark) using MediCapture (MediCapture, USA). Videos and cineloops were edited using Final Cut X (Apple Inc., USA)

\section{Biomed Central}


and uploaded in QuickTime Movie format (.mov) to an online video-hosting service (Vimeo.com, USA) for easy embedding into the app.

The app was developed using a previously described simple web-app method $[7,8]$ and the format enabled easy and multi-platform access. Screenshots of the final app are provided in Fig. 1 and the app is accessible from: http://akutul.cekuapp.dk
In conclusion, developing an educational smartphone app on focused ultrasound through nationwide collaboration across university hospitals was feasible.

This app cannot stand alone, nor replace supervision or courses in focused ultrasound, but it is a useful onsite e-learning supplement that may enhance learning outcomes.

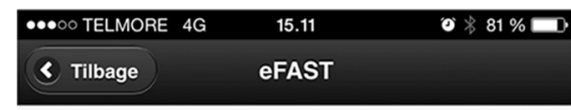

eFAST er en simpel, hurtig og sikker metode til diagnostik af pneumothorax, fri væske $\mathrm{i}$ pleurahulerne, perikardiesækken og peritoneum.

Instruktionsvideo
Patologi
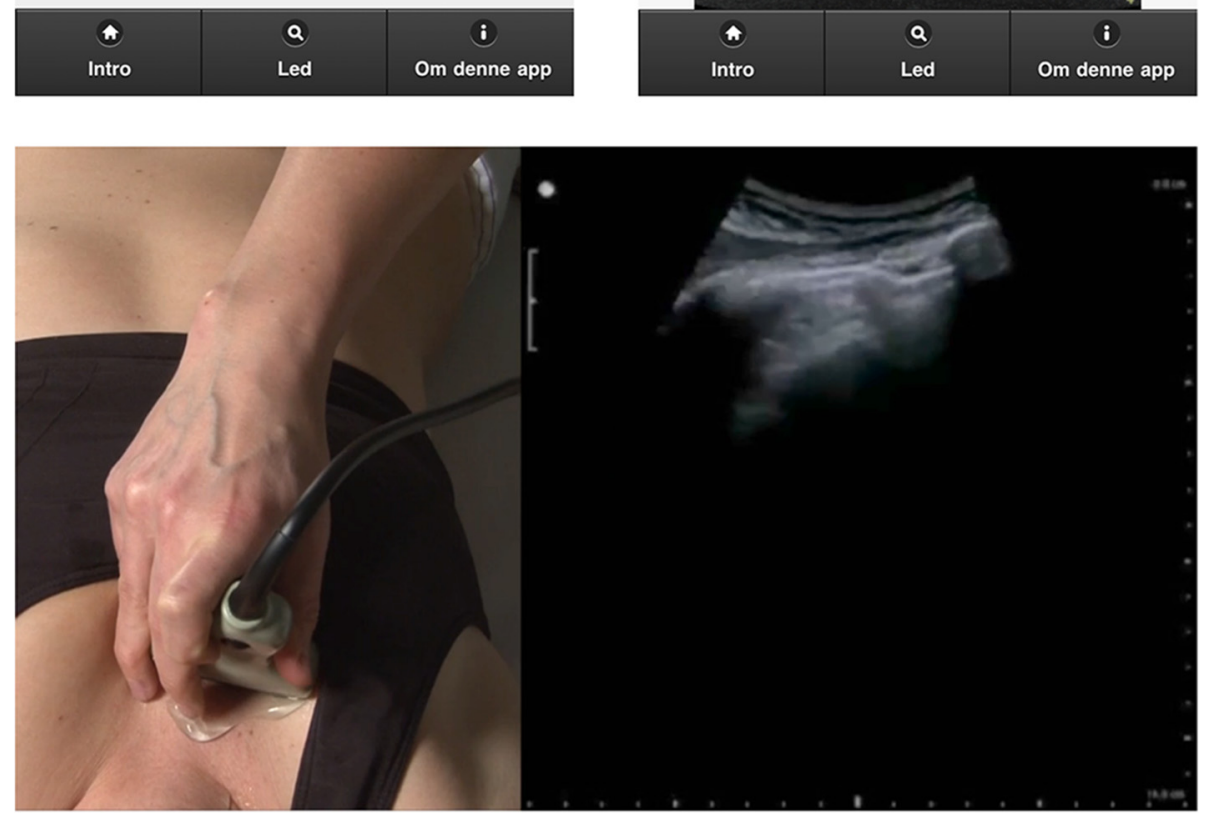

Fig. 1 Acute Ultrasound App: Example of app overview of eFAST (top, left) and examples of how to detect pathology (top, right). Example of an instructional video (bottom)

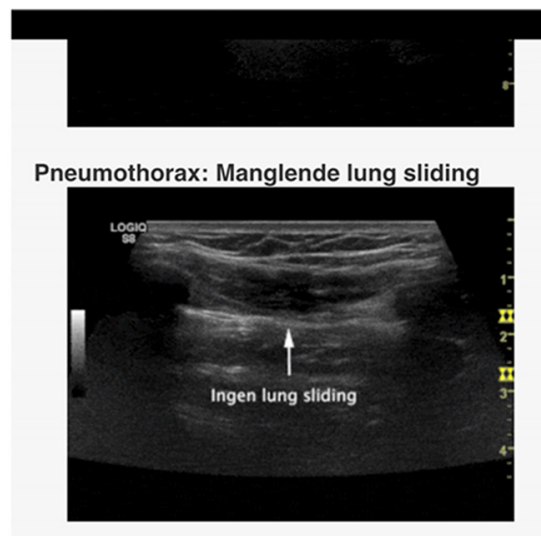

Patologi: Pneumothorax illustreret ved et lung point, som markerer zonen mellem lung sliding og manglende lung sliding

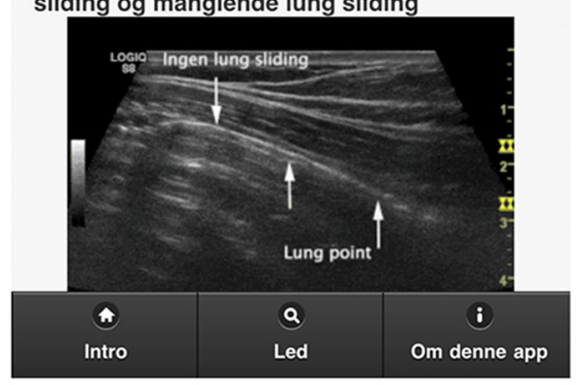




\section{Competing interests}

The authors declare that they have no conflicts of interest. The authors received funding from the Quality in Education Foundation "Undervisningskvalitetsfonden" at University of Copenhagen and Capital Region of Denmark.

\section{Authors' contributions}

KTF, YS, and TT contributed with the original idea. KTF, RA, ELB, MTB, OG, $\mathrm{CBL}, \mathrm{JW}$, and $\Pi$ authored all instructional material. YS developed the smartphone app. KTF, YS, and TT drafted the manuscript. All authors helped draft the final manuscript. All authors read and approved the final manuscript.

\section{Acknowledgments}

We are grateful for the help by medical students Ms. Iben Vind and Mr. Philip Nilsson to record and edit some of our videos. We thank medical students Ms. Liv Dyre, Ms. Laila Seidelin, Ms. Sif Helene Arnold, and Mr. Andreas Kohl for participating in our videos as actors.

\section{Author details}

${ }^{1}$ Centre for Clinical Education, Centre for HR, Capital Region of Denmark \& University of Copenhagen, Copenhagen, Denmark. ${ }^{2}$ Department of Neurology, Copenhagen University Hospital Herlev, Herlev, Denmark. ${ }^{3} \mathrm{Clinical}$ Eye Research Unit, Copenhagen University Hospital Roskilde, Roskilde, Denmark. ${ }^{4}$ Research Center for Emergency Medicine, Aarhus University, Aarhus, Denmark. ${ }^{5}$ Department of Anesthesia, Randers Regional Hospital, Randers, Denmark. ${ }^{6}$ Department of Anesthesia, Copenhagen University Hospital Herlev, Herlev, Denmark. ${ }^{7}$ Research Department, Prehospital Emergency Medical Services, Central Denmark Region, Aarhus, Denmark. ${ }^{8}$ Center of Clinical Ultrasound, Faculty of Health, Aarhus University, Aarhus, Denmark. ${ }^{9}$ Department of Radiology, Aarhus University Hospital, Aarhus, Denmark. ${ }^{10}$ Institute of Clinical Research, Aarhus University, Aarhus, Denmark. ${ }^{11}$ Institute of Clinical Research, University of Southern Denmark, Odense, Denmark. ${ }^{12}$ Department of Respiratory Medicine, Odense University Hospital, Odense, Denmark. ${ }^{13}$ Department of Emergency Medicine, Regional Hospital Herning, Herning, Denmark. ${ }^{14}$ Greenland Center for Health Research, University of Greenland, Nuuk, Greenland.

Received: 31 May 2015 Accepted: 1 June 2015

Published online: 20 June 2015

\section{References}

1. Gillman LM, Kirkpatrick AW. Portable bedside ultrasound: the visual stethoscope of the 21st century. Scand J Trauma Resusc Emerg Med. 2012;20:18.

2. Todsen $T$, Tolsgaard MG, Olsen BH, Henriksen BM, Hillingsø JG, Konge L, et al. Reliable and valid assessment of point-of-care ultrasonography. Ann Surg. 2015;261:309-15.

3. Laursen CB, Nielsen K, Riishede M, Tiwald G, Møllekær A, Aagaard R, et al. A framework for implementation, education, research and clinical use of ultrasound in emergency departments by the Danish society for emergency medicine. Scand J Trauma Resusc Emerg Med. 2014;22:25.

4. Kotagal M, Quiroga E, Ruffatto BJ, Adedipe AA, Backlund BH, Nathan R, et al. Impact of point-of-care ultrasound training on surgical residents' confidence. J Surg Educ. 2015; doi:10.1016/j.jsurg.2015.01.021.

5. Hempel D, Sinnathurai S, Haunhorst S, Seibel A, Michels G, Heringer F, et al. Influence of case-based e-learning on students' performance in point-of-care ultrasound courses: a randomized trial. Eur J Emerg Med. 2015; doi:10.1097/MEJ.0000000000000270.

6. Bullock A, Dimond R, Webb K, Lovatt J, Hardyman W, Stacey M. How a mobile app supports the learning and practice of newly qualified doctors in the UK: an intervention study. BMC Med Educ. 2015;15:1-6.

7. Subhi $Y$, Todsen T, Ringsted C, Konge L. Designing web-apps for smartphones can be easy as making slideshow presentations. BMC Res Notes. 2014;7:94

8. Subhi Y, Foss KT, Henriksen MJV, Todsen T. Development and use of web-based apps. Tidsskr Læring og Medier. 2014;7:12.

\section{Submit your next manuscript to BioMed Central and take full advantage of:}

- Convenient online submission

- Thorough peer review

- No space constraints or color figure charges

- Immediate publication on acceptance

- Inclusion in PubMed, CAS, Scopus and Google Scholar

- Research which is freely available for redistribution

Submit your manuscript at www.biomedcentral.com/submit 